\title{
From a Guided Teacher into Leader: A Three-Stage Professional Development (TSPD) Model for Empowering Teachers
}

\author{
Anat Abramovich ${ }^{1} \&$ Shirely Miedijensky ${ }^{2}$ \\ ${ }^{1}$ Gordon Academic College, Haifa, Israel; Malam Headquarters, Israeli Center for Scientific Technological \\ Education; Technion-Israel Institute of Technology, Haifa, Israel \\ ${ }^{2}$ Oranim Academic College, Tivon, Israel; Shamir Research Institute, Haifa University, Israel \\ Correspondence: Anat Abramovich, Gordon Academic College, Haifa, Israel; Malam Headquarters, Israeli \\ Center for Scientific Technological Education; Technion-Israel Institute of Technology, Haifa, Israel.
}

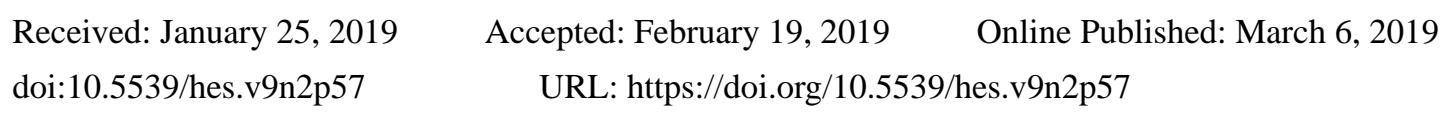

\begin{abstract}
A three-stage professional development (TSPD) model for training experienced teachers to become teachers' leaders is presented here, along with a study assessing its value. The three stages of the model are: a "basic training" stage, a "master-teacher" stage, and an "independent implementation" stage. This qualitative study included open questionnaires and interviews of participants and course leader after the various stages. Statements were classified accordingly to three main themes: 'teachers as pedagogues', 'teachers' involvement in environmental science (ES) community', and 'teachers' as leaders'. Results show that participating in the TSPD course enabled teachers to unify into one coherent community with similar goals, increased their self-confidence, empowered them as teachers by improving classroom function, and intensified their abilities to act as teachers' leaders. This model, although tested on environmental science teachers, is applicable to any teacher community.
\end{abstract}

Keywords: professional development, leadership, teacher empowerment

\section{Professional Development Courses and Leadership Skills}

\subsection{The Need for Teaching Leadership Skills}

Many professional development (PD) courses for teachers focus on the acquisition of content and pedagogical content knowledge, sometimes with the addition of leadership skills (e.g., Hofstein, 2005; Sprott, 2019; Van Driel \& Berry, 2012). Course mentors assume that by the end of the course, teachers will have accrued enough confidence in their abilities to allow them to become better teachers and leaders among their colleagues (Harrison Berg, Carver, \& Mangin, 2014; Hofstein, 2005). This approach has had some success (e.g., Borko, Koellner \& Jacobs, 2014; Hofstein, 2005; York-Barr \& Duke, 2004), but it is not uncommon for teachers to acquire content and pedagogical content knowledge, yet experience obstacles in their path to becoming leaders or master-teachers. Some refrain because they do not feel obliged to do so; others feel they are not properly qualified or lack leadership skills or self-confidence to mentor their colleagues, and some experienced unpleasant emotions during the PD period (Dawkins \& Dickerson, 2007; Gaines et al., 2019; Harrison Berg et al., 2014).

We studied a three-stage professional development (TSPD) model that took into consideration those gaps between what is expected from teachers after participating in a PD course and what happens in actual fact. The aim of the course developers was to develop content knowledge, teaching skills, and assessment tools for environmental science (ES) teachers while simultaneously enhancing their skills as leaders among their colleagues. Based on these goals, the Israeli National Center for Biology \& Environmental Science Teachers designed a long-term PD course (two academic years). However, towards the end of this course, the course developers realized that despite their meticulous preparation and the improvement in the participants' performance as pedagogues, there was no observable improvement in their leadership abilities. They therefore decided to add two more stages alongside instruction of teaching and assessment techniques. First, additional focus on leadership skills by asking each participant to mentor two novice ES teachers, thus allowing the mentoring process to come under professional supervision. Second, a field implementation stage under the guidance and supervision of the ES superintendent and her staff was added. Even though this TSPD model came into being in stages, it seems to be the correct form for empowering teachers. 
The research question guiding this paper is "what are the teachers' insights regarding their performances as pedagogues and leaders (guiding ES teacher colleagues) after participated in TSPD program?" In other words, we examined the changes in teachers' abilities as teachers, leadership skills, self-efficacy, and confidence.

Our assessment included the teachers' insights, that were backed up with the course leaders' opinions and documents collected by the researchers during the process.

This study explored the entire process, examining each stage separately and also all three stages as a whole to determine if this model offers an effectual and potent form of PD to empower teachers as leaders.

\subsection{Relevant Scholarship: Science Teachers' Professional Development}

Present-day reforms in science teaching encourage teachers to engage their students in scientific investigation, create hands-on activities, and use technological tools. These changes mean that teachers must enhance their knowledge, teaching skills, and assessment skills in these areas (Dori \& Herscovitz, 2005; Loucks-Horsley et al., 2009; Tal \& Argaman, 2005). For example, Tal and Argaman (2005) conducted a PD course that required environmental science teachers to learn how to mentor high school students in field-based inquiries that would count as part of their (the students') final grade. Dori and Herscovitz (2005) developed a long-term PD program for chemistry teachers that, alongside the usual science and chemistry topics, included two extensive additions: (1) teachers taught their students using student-centered learning materials they (the teachers) had designed; (2) teachers, after applying their knowledge, discussed and analyzed case studies as a group. This PD program was deemed successful, as the participants demonstrated that they could develop appropriate interdisciplinary activities. Other PD programs have included leadership skills alongside content knowledge, and teaching and assessment skills with the goal of improving how the teachers function amongst their faculty or professional colleagues (see, for example, Harrison Berg, 2014; Howe \& Stubbs, 2003).

Hofstein (2005) describes a long-term PD program for chemistry teachers on the subject of implementing new curricula that includes leadership skills in addition to content and pedagogical content knowledge. He reported that 10 of the 40 teachers who participated in this PD program went on to become tutors and leaders in chemistry education. Unfortunately, there was no further follow-up, hence no data regarding how successful those teachers ultimately became in the field of chemistry education or how long the new activities lasted.

The question arises: How can teachers be properly trained to become highly effective educators and to simultaneously act as master-teachers? Researchers have suggested different requirements to meet these goals physical conditions (where and at what points during the year, the course takes place), economic conditions (allocated funds), participants' qualifications (knowledge and beliefs), subject matter (curricula) and so forth. However, the one thing almost all agree on is the need for the teachers to obtain long-term experience in acquiring and actually implementing new teaching and assessment strategies in collaboration with colleagues (Bell \& Gilbert, 1996; Desimone, 2009; Loucks-Horsley et al., 2009; Supovitz \& Turner, 2000).

In the present case, the course developers took into consideration participants' needs for becoming better teachers and leaders and chose a framework suggested by Bell and Gilbert (1996), who argued that teacher development is an interweaving of social, personal, and professional aspects that are mutually dependent.

\subsection{Relevant Scholarship: Educational Leadership and Teacher Empowerment}

How is leadership defined? According to Gallagher (2012), some scholars consider leadership to be a process in which individuals and groups deal with various problems. For other scholars, leadership is the ability of an individual to influence, motivate, and enable others to act and contribute to the success of their organization (House, 2004), or a process whereby an individual influences a group of peers to achieve a common goal (Northouse, 2010). While both these scholars mention the influence of the individual on the group, Northouse emphasizes that a leader strives to create a group that shares a commitment to a common goal.

Nevertheless, these definitions are rather general. Specific characteristics are required to define effective leadership. Fullan (2003) identified five characteristics of a leader: (1) teamwork and developing others, (2) drive and confidence, (3) vision and accountability, (4) influencing tactics and politics, and (5) thinking styles (i.e., understanding the overall picture). Wetzler (2010) claimed that an educational leader must have the ability to set manageable goals, motivate students and colleagues to become involved in these goals, plan purposefully, execute effectively, continually increase effectiveness, and work relentlessly.

Environmental leaders are guided by a personal belief in the value of nature and therefore must also put environmental knowledge and concern into action (Fortino, 1997). The goal of the environmental leader should be to convince all levels of society of the need for collective engagement to face local and global problems (Dietz Dolšak, Ostrom \& Stern, 2002; Gallagher, 2012). Manolis et al., (2008) claim that effective environmental 
leaders will integrate conservation science into policy, management, and society-at-large, while inspiring and nurturing future leaders. Hargreaves and Fink (2004) have contributed the "seven principles of sustainable leadership": (1) create and preserve sustainable learning, (2) secure success over time, (3) sustain the leadership of others, (4) address issues of social justice, (5) develop (rather than deplete) human and material resources, (6) develop environmental diversity and capacity, and (7) actively engage with the environment. As for teacher leadership, York-Barr and Duke (2004), suggested this definition: "Teacher leadership is the process by which teachers, individually or collectively influence their colleagues, principals, and other members of school communities to improve teaching and learning practices with the aim of increased student learning and achievement" (p. 287-288).

In order to empower leaders, in particular teacher leadership, one must first consider the focus of their leadership (organizational, educational, societal, environmental, etc.) and then the personal characteristics required. Popper, Amit, and Gal (2004) discovered that potential leaders have more internal locus of control, lower levels of anxiety, higher self-efficacy, and more optimism (self-confidence). Yet, the researchers admitted that potential alone is not enough: the desire, availability, and opportunity to take leadership are also required.

In our study, the focus was on how to empower ES teachers: for example, to become better teachers and leaders among their ES colleagues. Therefore, the professional development framework consisted of social, personal, and professional aspects where teachers experienced individual development (teaching and assessment skills, studying issues of environmental knowledge, sustainability principles, and social justice) and team development skills (leadership skills to implement among their ES-teacher colleagues) (Bell \& Gilbert, 1996; Fullan, 2003; Hargreaves \& Fink, 2004; York-Barr \& Duke, 2004).

\subsection{Relevant Scholarship: Environmental Science in Israeli High Schools}

Science is a mandatory subject in Israel elementary and junior high schools (grades 1-9) but is an elective in high school (grades 10-12). The main sciences offered in high school are biology, chemistry, and physics. A small number of students choose to major in environmental sciences (ES); quite often, schools urge lower-achievement students to consider majoring in ES.

During the last decade, the ES curriculum in Israel has changed dramatically. The national curriculum directs the development of learning materials and defines the content to be learned, the skills to be developed, and the assessments to be employed. The main considerations behind the new ES curriculum are to increase relevancy, improve the connection between students and their social and physical environments, promote higher order thinking skills, and encourage the development of pro-environmental attitudes and behavior (Israeli Ministry of Education, 2007). The ES curriculum recognizes the diversity of ES students and acknowledges the unique potential that environmental topics have to bridge social gaps.

The ES high school program comprises core and mastery units (60\%) and two inquiry-based units (40\%). The core unit focuses on conceptual knowledge and ES concepts spanning six topics: ecosystems and biodiversity, water, air, waste, noise and radiation, and ecological design. The mastery unit builds on the information learned in the core unit and emphasizes quantitative aspects and the inter-relationships between the scientific and the social areas (economy, law, ethics, public health policy, etc.). Assessment is based on an external matriculation exam $(50 \%)$ and the teacher's continuous assessment throughout high school (50\%).

The two inquiry-based ES units are "Ecotop," where students are required (frequently in pairs) to investigate an environmental problem/issue, and "Environmental Workshop," where the entire class investigates three different environments (e.g., a river, an industrial area, and an urban system). The aims of both units are to develop students' scientific skills and knowledge and to encourage them to care for and feel responsible for their environment and society through active learning, hands-on experience, and genuine involvement. Assessment of this unit is by internal school assessment (Israeli Ministry of Education, 2016).

The above curriculum structure increased the need for ES teachers who are able to deal with a variety of subjects and skills required by the curriculum. Such teachers must not only educate ES students about environmental issues, but also enhance their students' environmental awareness and care for the physical and social environment. Without any specific ES training, teachers are faced with dealing with the complexity of teaching ES on their own.

\section{Method}

\subsection{The Three-Stage Professional Development (TSPD) Model}

ES teachers ought to be introducing a complex, multifaceted subject, where science, technology, society, and nature all come into play to teach about and understand the environment and ways to deal with its deterioration. 
In actual fact, however, Israeli ES teachers are obligated to abide by the prescribed ES curriculum (which focuses on biodiversity, waste problems, water quality, and so forth), act as mentors for their students during the inquiry-based ("Ecotop") unit and be capable of conducting a class-sized investigation outside the classroom ("Environmental Workshop" unit). These factors were taken into consideration by the TSPD course planners. Their main goals were to not only to enable teachers to improve their teaching and assessment techniques, but also to enhance their leadership skills so that after the two-year PD program, the teachers would be able to guide their colleagues and eventually become leaders in their ES teacher community.

The authors of this paper designed a three-stage professional development (TSPD) program that began with "basic training," continued into "master training," and culminated with experiential "independent implementation." The basic training stage, as mentioned above, was based on Bell and Gilbert (1996), who argued that teacher development is an interweaving of social, personal, and professional aspects that are mutually dependent. Our "basic training" stage had three main facets: social (how teachers should interact with their peers and how to define the essence of the teacher's role); personal (to guide teachers in adjusting to the changes they will actually experience in the classroom and to boost self-empowerment); and PD (to broaden the participants' scientific and pedagogical knowledge). The PD portion ran in parallel to the personal and social ones. Course planners assumed that by the end of the TSPD course, the teachers would have confidence in their abilities to become better teachers and, most importantly, to act as leaders within their ES teacher community.

Below, we present the different stages of the TSPD model, the general features of which were presented at the April 2016 AERA (American Educational Research Association) conference (Abramovich, \& Miedijensky, 2016).

\subsubsection{Stage 1: "Basic Training"}

The "basic training" course spanned two academic years and comprised 112 hours: 10 meetings (5-6 hours each) in the first year and 11 meetings (4-6 hours each) in the second year. Topics covered environmental dilemmas (e.g. air and water pollution, open-spaces vs. housing requirements) and sustainability principles.

The "Ecotop" research unit was covered in detail: participants developed a scoring rubric that would benefit other ES teachers and also developed comprehensive study units by researching information and ES activities on the internet. These units were presented to their peers and included teaching methodology, appropriate learning materials, and assessment procedures.

For the "Environmental Workshop" unit, participants were taken on field trips and conducted field inquiries to become familiar with different environments. They learned about each site and were taught skills to handle a large high school class at the site.

Assessing the teachers' progress at the end of the "basic training" stage revealed that although it contributed to the teachers' individual professional development and led to some fruitful collaboration and networking, it did not provide the skills necessary to guide their colleagues. For this reason, we added the "master training" stage.

\subsubsection{Stage 2: "Master-teacher (MT) Training"}

"MT training" comprised 56 academic hours. The goal was to instill leadership skills by having participant teachers - under the supervision of two mentors - act themselves as mentors (MTs) for two novice teachers. One of the course mentors specialized in ES and pedagogical content knowledge, and the other in guiding skills; they were available to respond to any questions or dilemmas that arose. The course leaders, for their part, challenged each MT to use their knowledge and skills to guide the novice teachers and take overall responsibility for their progress and welfare. The MTs planned the content of the meetings between them and their novice teachers ahead, and included learning materials, conducting and handling field trips and lab experiments, and teaching and assessment strategies.

The MT training stage included group meetings to teach the participants guidance skills, meetings between the MT participants and their novice teachers, and semi-personal meetings, when two or three participants met each time with course leaders. This stage offered participants the opportunity to sense if tutoring came naturally to them and if it might be a role they would wish to be assigned to in the future.

The fact that every MT was able to get actual practice in the field and immediate support if confronted by problems empowered them as leaders. The novice teachers also benefitted greatly, as they had a mentor to guide them if they felt uncertain or had teaching difficulties.

\subsubsection{Stage 3: "Independent Implementation"}

The "independent implementation" stage is an ongoing process. MTs who desired so were assigned a particular 
role by the ES superintendent based on field requirements. Even though the participants had, ostensibly, already learned to be independent MTs, they still benefitted from the support of the ES superintendent and could consult her regarding any difficulties or indecisions. Thus, uncertainty and anxiety were reduced, self-confidence was increased, and the participants were empowered.

The TSPD model is illustrated in figure 1.

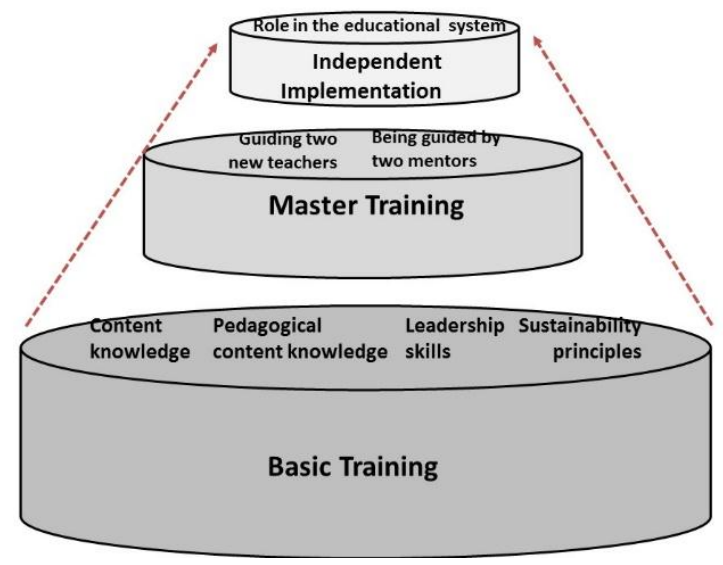

Figure 1. The TSPD model

Figure 1 illustrates each stage of the three-stage model, summarizing briefly the main points in each stage.

\subsection{Research Approach}

The study was qualitative in nature and based on guidelines described by Lincoln and Guba (2000) and Tuckman and Harper (2012). Participants' insights on the various stages of the TSPD were determined by means of open-ended questionnaires and intensive interviews. These allowed us to determine the changes that the participants experienced in their classroom and among their ES teacher community as a result of the PD. As for the "MT-training" stage, we revealed their experiences with respect to mentoring novice teachers. Also, we assessed how participants who took on roles as leaders in the school and classroom in the ES educational system implemented those roles (taking charge of educational programs, developing learning materials, etc.). Since self-assessment can be considered to be a weak tool for evaluating TSPD, we also interviewed the course leaders and collected documents that could clarify the process.

\subsection{Participants}

Thirty-one experienced ES teachers, 15 males and 16 females participated in the "basic training" stage. They were all university graduated in science (biology or chemistry), seven of them had a master's degree in science education. Their teaching experience was between 10 to 20 years. Of these 31 participants, 14 were interested in continuing on to the "MT training" stage. As for the third stage, at the time of this report, nine participants (of the 14) are either working under the supervision of the ES superintendent as teacher mentors, are members of educational committees, or are serving as MTs for novice teachers.

\subsection{Research Tools}

\subsubsection{Questionnaire 1}

All first-stage (basic training) participants $(\mathrm{N}=31)$ received an open-ended questionnaire via google drive. They provided personal information (name, email address, educational degree, school details) and agreed to be interviewed. They were asked to describe any professional development courses they had previously undergone (for the purpose of being appointed to duties in the educational system or studying toward higher degrees); their class management, teaching, and assessment techniques; their strategies for implementing sustainability principles among students; and their involvement in the ES teacher community. They were also asked to self-grade their environmental literacy (according to definitions we provided) and justify their grade. Finally, they were asked for insights regarding the "basic training" stage and to assess how it contributed to performance changes in their classroom or within their ES teacher community. 


\subsubsection{Questionnaire 2}

Participants (N=14) in the "MT training" stage received, also via google drive, a second open-ended questionnaire in which they were asked to describe their meetings with the novice teachers, assess their contributions to them, and tell about their personal gain from the guiding process. They were also asked if they went on to the third stage and, if so, what role they had been assigned. In addition, participants were asked to describe what they believe "leading teachers" are and how they can contribute to the ES teacher community. Finally, they were asked to evaluate the structure of the TSPD model and give their opinion on its suitability for empowering teachers.

\subsubsection{Interviews}

Semi-structured interviews were conducted with (1) five (out of the nine) teachers who had been assigned roles by the ES superintendent and (2) the course leader who led the basic training stage. (She also was a leader of the "master-training" stage.)

Interview questions were based on the interviewees' answers to their questionnaires, with an emphasis on their role(s) in the educational system. The interview with the course leader also asked for insights from the planning stage and the guiding process.

Each interview lasted from 60 to 90 minutes. They were scheduled in advance and took place in a location convenient for the respondents. All interviews were recorded and transcribed.

\subsubsection{Documentation}

Documents from the different stages of the TSPD program were collected by the researchers. From the "basic training stage: lesson plans, lesson logs (what was taught in actual fact), teaching materials, teachers' assignments during the meetings. From the master-training stage: records of meetings between the MTs and their novice teachers.

The documents allowed us to follow the different stages retrospectively and to correlate participants' answers to the questionnaire and the interviews. All the above instruments allowed data triangulation.

Requisite standards of ethical conduct in research were complied with throughout the study, particularly with respect to full confidentiality of the participants and all documentation (Marshall \& Rossman, 2014).

\subsection{Data Analysis}

\subsubsection{Analysis of Questionnaire 1}

Text from the open-ended questions in the questionnaire and relevant documentation (insights about the guiding process) were compiled and analyzed by content analysis. Participants' statements were classified into two main independent categories (as in the questionnaires): (1) teachers as pedagogues - a) how they apply learning and assessment tools that were introduced during the course, and b) how they implement sustainability principles among their students; and (2) teachers involved in the ES teacher community (guiding, tutoring, sharing teaching materials, developing new materials).

Actions regarding environmental awareness and behavior were further analyzed in conjunction with the VBN (Value-Belief-Norm) theory for environmentally responsible behavior (Stern, 2000; Stern, Dietz, Abel, Guagnano \& Kalof, 1999). The VBN theory suggests a causal chain of behavior that progresses from relatively stable, central elements of an individual's personality and belief structure to responsibility for taking action. We classified two levels: Level 1: responses expressing general care for the environment with only declarative values and beliefs; Level 2: responses expressing deep understanding regarding the complexity of the environment combined with values and systemic vision (see also, Abramovich \& Loria, 2015).

Teacher involvement in the ES teacher community included three aspects: (1) cognitive (learning materials, class management), (2) affective (encouraging conversation, resolving personal conflicts), and (3) environmental (engaging teachers with environmental activities such as recycling and managing ecological gardens).

\subsubsection{Analysis of Questionnaire 2}

Questionnaire 2 was analyzed inductively. Questions concerning the "MT-training" stage were analyzed according to participant insights and gains regarding their roles as moderators and regarding their moderated (novice) teachers. Eight themes were identified, five of them related both to the moderators and the moderated (i.e. improvement in content knowledge). This will be expounded in more detail in the results section.

The participants' opinions of the TSPD model were classified as either "fully satisfied" or "satisfied with some reservations" (none of the responses indicated that any of the participants were dissatisfied). Their answers 
concerning what makes a "leading teacher" were evaluated according to how the respondents felt that they had become empowered to become leaders in the ES teacher community.

\subsubsection{Analysis of the Interviews}

The interviews, conducted with five of the nine teachers who continued the program, explored their feelings regarding the entire training process, with an emphasis on their experience mentoring the novice teachers (MT training stage) and their role in the system (independent implementation stage). From their answers regarding guiding novice teachers, eight themes were derived: improvement in content knowledge, improvement in pedagogical content knowledge, affective elements (friendship, candid conversation, acceptance), mutual contributions, self-empowerment, a sense of obligation towards the system and novice teachers, empowering novice teachers to become part of the ES teacher community, and someone to turn to without fear of being judged.

The interview with the course leader analyzed her insights from both the planning stage and the guiding process.

In order to establish credibility, the two researchers independently coded the various categories and compared findings. Agreement was $90 \%$.

\section{Results}

The results for each stage are presented separately. For the "basic training" stage, we analyze how the teachers acted as educators among their students and among their colleagues in the ES teacher community. In the "MT training" stage we present teachers' insights and gains from the process. For the "independent implementation" stage, we describe teachers' views concerning their roles in the ES educational system. Then we introduce participants' views on the model and what the term "leading teacher" means to them. Finally, we report the course leader's opinion of the whole process.

\subsection{Stage 1: Basic Training}

\subsubsection{Teachers as Educators: Teaching and Assessment Strategies}

Teaching strategies. All the teachers stated that they began implementing new teaching strategies after participating in the basic training stage. Of the 36 statements mentioned $47 \%$ referred to technological applications such as films or lab sensors. Sonia, for example, wrote: "I upgraded my teaching strategies by using apps such as Google Docs [for cooperative work], Kahoot [for giving quizzes], or ThingLink. I also had them gathering information from their smartphones". Thirty one percent referred to incorporating field trips into ES lessons, as Omar wrote: "I combine field into my teaching. This arouses interest and leads to meaningful learning". Other $22 \%$ referred to environmental dilemmas or the use of scientific articles, as Amjad wrote: "I use a variety of strategies; I emphasize environmental articles dealing with dilemmas". The fact that less statements dealt with scientific articles or with environmental dilemmas in the class may perhaps be because these are already routine strategies in ES classes and so were not regarded innovative. In Sahara's words: "The truth is, I always use scientific articles in my teaching to stress facts and learn from real events..."

Assessment in the classroom. About $61 \%$ of the participants $(\mathrm{N}=31)$ stated that they had introduced alternative assessment methods such as evaluating reports about environmental dilemmas or debates, essays describing impressions and conclusions after a field trip, or films about environmental issues. For example, Sami wrote: "...I used to only give them tests. Now I also grade students on their participation in debates, group participation, and solutions they propose for environmental dilemmas." Some participants mentioned using embedded assessment within the learning process, enabling their students to resubmit their assignments after correction. Still, 39\% of the participants declared that there was no change in their methods of class assessment. This might be due to them being experienced teachers or because teaching ES allows the use of various types of assessment methods.

\subsubsection{Teachers as Educators: Implementation of Sustainability Principles}

We next analyzed the question regarding how teachers implemented sustainability principles amongst their students, for which 44 statements were obtained Teachers expressed a variety of methods they used: $54 \%$ of the statements related to actual actions taken by students in favor of the environment (environmental behavior), $21 \%$ related to embedding sustainability principles within ES topics (environmental dilemmas or environmental events such as heavy storms or drought), $16 \%$ concerned developing environmental awareness among students, and $9 \%$ described linking sustainability topics to field trips (assuming that actually seeing how humankind influences the environment is the best way to learn the importance of sustainability).

Regarding the development of environmental awareness, Muneer wrote: 
Throughout the entire learning period, students face environmental dilemmas, learn about the natural environment, how men influenced it, and what can be done - to be exact, what they can do. We are witnessing the development of environmental awareness and responsibility among our students, and they are spreading this awareness to their peers.

A second distribution analysis was performed regarding permanent vs. discrete actions, and this showed that approximately $67 \%$ of the statements involved permanent actions: conserving water and electricity, recycling, taking care of public sites adjacent to the school (parks, empty lots, etc.), cleaning the schoolyard, and planting around the school. The others involved specific days or events, such as earth day (April 22 of each year, in which people all over the world are meant to take action connected to social and environmental welfare). Sonia described a number of activities that her students have done:

Each year, my ES students are in charge of spreading awareness throughout the school of the importance of taking care of the environment. In class, they encourage recycling, water conservation, and other actions that express concern for the environment. I sense their concern for the environment. For example, after meeting volunteers from Eco-Ocean, an environmental association, the students prepared lessons based on what they had experienced and taught pupils in elementary school.

Sonia's words exemplify the difference between permanent habits and specific actions. Moreover, the overall impression is that her students are fully aware of environmental problems and feel responsible for reducing some of the damage.

A third analysis examined how the implementation of sustainability principles aligned to VBN theory by analyzing the statements according to the level of care for the environment they demonstrated (Abramovich \& Loria, 2015; Stern, 2000; Stern et al., 1999). Of the 28 (out of 31) participants who described their implementation of sustainability principles among their students, 19 expressed only declarative values and beliefs regarding care for the environment (level 1). The other 9 expressed deep understanding regarding the complexity of the environment combined with values and systemic vision (level 2).

An example of a level-1 statement is Amir's: “I deal with sustainability principles when I teach about recycling and the need to use public transportation in order to care for the environment. We had some successful activities concerning the welfare of the environment."

An example of a level-2 statement is Meny's:

My students often tell me that they have a lot of influence on their family and explain to them the need for taking care for the environment and how every action - even one as simple as recycling - can greatly influence and benefit the environment. Their values are also apparent in the classroom when they show willingness to take part in environmental projects. They know that even small actions can make a difference to the environment.

Both Amir and Meny wrote about class activities that involved taking care of the environment, but Meny emphasized the importance of acting in favor of the environment and stressed that his students volunteered because they appreciated that their actions would benefit the environment.

Based on the data gathered, we concluded that the basic training program enriched the participants' knowledge of teaching and assessment tools and enabled them to implement sustainability principles among their students.

\subsubsection{Teacher Involvement in the ES Teacher Community}

We examined the teachers' involvement in the ES teacher community from the cognitive, affective, and environmental aspects that the teachers focused on. Of the statements gathered, $65 \%$ related to the cognitive, $16 \%$ addressed the affective, and $19 \%$ dealt with the environmental aspects. These results are not surprising, since we can assume that contributions connected to learning materials or class management (cognitive) are easier to implement than encouraging other teachers to deal with their own personal conflicts (affective) or changing behavior (environmental). It is important to note that some teachers reported contributing in all three aspects. For example, Sami related his contribution to the ES teacher community as follows:

There is one other ES teacher in my school, and I feel I have become his mentor concerning ES materials [cognitive], environmental activities [environmental], and class management [cognitive]. I won't exaggerate if I say that other teachers consult with me every time they are confronted with an educational or a personal conflict [cognitive \& affective].

Regarding leadership, we could find scarcely any signs of this from in the teachers' answers. Only three participants mentioned that they were actually guiding novice teachers, but none had initiated the move: the 
novice teachers who they were helping had turned to them to ask for help.

In summary, after the basic training stage, participants began using a variety of new teaching methods and assessment tools, implementing sustainability principles, and becoming more involved in their ES teacher community. However, even though some training during this stage dealt with leadership and leading, only three teachers actually became involved in guiding novice teachers, and even this was not on their own initiative. Disappointingly, only 14 teachers felt the need to accept the challenge of further PD training (Stage 2) to help them become leaders in the ES teacher community.

\section{Stage 2: Master-teacher (MT) Training}

Fourteen teachers underwent guidance to qualify them to lead novice teachers through the "teaching maze." The insights provided by the MTs regarding their role as mentors to novice teachers show they believe that they clearly helped improve the others' knowledge and class-management skills. Some even created frameworks for long-term support. Others emphasized the quality of mutual collaboration.

Alongside this, MTs also reported an improvement in their own knowledge, skills, self-confidence, competence, and accountability. Table 1 illustrates the contribution of this stage to both MTs and novice teachers (based on the MTs' answers).

Table 1. The contribution of the master-teacher stage: Moderator/moderated gains

\begin{tabular}{ll}
\hline Moderator (master-teachers) & Moderated (novice teachers) \\
\hline Improvement in content knowledge (CK) & \\
Improvement in pedagogical content knowledge (PCK) & \\
$\begin{array}{l}\text { Affective elements (friendship, candid conversation, acceptance) } \\
\text { Mutual contribution }\end{array}$ & \\
$\begin{array}{l}\text { Self-empowerment } \\
\text { Sense of obligation towards the system and novice teachers }\end{array}$ & $\begin{array}{l}\text { Someone to turn to without } \\
\text { Empowering novice teachers to become part }\end{array}$ \\
of the ES teacher community & \\
\hline
\end{tabular}

All the MTs stated that they advised their novice teachers on how to prepare introductory presentations about water problems, waste management, air pollution, and so forth for their classes. Their guidance also included instructions for a variety of teaching tools; tips on how to manage lessons, handle field inquiries and conduct workshops; and assessment methods (exams or alternative assessment). The MTs admitted that in order to be efficient, they also needed to improve their own environmental knowledge and skills. For example, Sue stated in her interview:

In order to be able to guide the novice teachers, I had to prepare very carefully. I know it seems like something a beginner has to do, but still, I felt I had to do it. As a result, not only did my guided teacher improve his knowledge and skills [CK and PCK], I improved as well. I also feel I supported them emotionally with school and private affairs [candid conversations]. They knew they can ask me anything, anytime [someone to turn to without fear or being judged].

Some of the MTs reported that the experience had become one of mutual support: sharing learning materials and exam questions, consulting with one another about particular teaching strategies or how to handle fieldtrips, etc. Some enjoyed the spirit of "teamwork." Others even felt they gained a friend. For example, Farid said: "From day one, we were friends. We talk every week about many topics - not all of them about ES. We even text each other jokes. I did the guiding mission with full intention and support" [friendship and sense of obligation].

According to the responses, the most powerful contribution of this stage was the sense of self-empowerment endowed to novice teachers and MTs alike. The novice teachers, on one hand, learned techniques to manage, teach, and assess their classes, and to manage their time. Above all, the knowledge that someone (their MT) was standing behind them enabled them to face their class with full confidence and to feel empowered. On the other hand, the MTs, by helping and being able to solve the novice teachers' problems, felt a sense of self-efficacy and empowerment.

It is clear that this stage enriched both novice teachers and MTs alike. For example, Merry stated: "Mentoring enhanced my self-confidence! I discovered I was capable of contributing pedagogically as well as providing emotional support. Mentoring also helped me think differently - out of the box - and even improve my own teacher-student relationships" [empowerment]. 
Moony pointed out that the key for success was the initiation and willingness of the novice teachers to ask for support. He sums up his experience with his two novice teachers:

I helped my novice teachers in every way. I introduced them to a variety of teaching and assessment tools, gave them techniques for class management, and shared with them all my teaching material [CK \& PCK]. We communicated on a constant basis. I was the one they turned to when they had any issue with problematic students in class, when they had to face the school principal to ask for more teaching hours to finish a class project, or when they had to send a report to their superintendent [someone to turn to without fear or judgement]. Today, I can say that my assistance really helped them gain confidence and improve a lot as ES teachers [sense of obligation]. Nevertheless, their achievements were also due to their eagerness to succeed, the guts they had to ask for help, and their willingness to share their weaknesses concerning their abilities as ES teachers without shame or fear.

Three of the MTs admitted that they had difficulty communicating with their novice teachers or felt that the novice teachers were not committed or eager for help. In Zoey's words: "A. was very busy and didn't feel committed to the process. I sometimes felt like I was 'chasing' after him, trying to help..."

To sum up, the feedback from the MTs demonstrated that the process was a positive one for them. They felt that they had offered a significant amount of support for the novice teachers, "paving the road" for them into the world of teaching. Nevertheless, some of the MTs felt frustrated that, despite the affirmative results, their novice teachers did not respond eagerly.

\subsection{Stage 3: "Independent Implementation"}

At the time of this writing, the ES superintendent has so far assigned 9 of the 14 teachers to assist her in handling ES in the educational system. Four are in charge of ES educational programs, three are MTs under her supervision, one (Sue) was assigned to plan and lead an educational program for ES teachers, and one has become involved in professional ES committees (Zoey).

In her interview, Sue spoke about her insights from the PD course and how it transformed her as a MT and as a teacher at school:

During the PD course, I learned that I, as a master-teacher, must get to know my guided teachers. I mean really know them, not just to teach them professionally, so that I would be able to unify them into one group with mutual goals. However, I haven't really succeeded. I tried to arouse the participants' responsibility to the course's missions and toward each other. This worked for my colleagues and me during the PD course and I thought it would be the same now, but to no avail. I tried consulting with my course leader and the ES superintendent, but with this particular group of teachers, I just haven’t managed to become successful as course leader. I am not giving up, though. I will try to do better on the next course. I try to do the same with my school students, meaning working together on a shared mission, letting them take charge and deciding together what should be done. It's not an easy move, but after a while I can see the change in my students. They become independent learners who work together on mutual targets.

Sue's words illustrate how meaningful the preparation she experienced was: even though the first course she led was not a great success, she has full confidence in herself and is willing to lead another one. Her confidence in her capabilities is also, no doubt, due to the fact she can consult with her PD course leader or the ES environmental superintendent.

Zoey replaced the superintendent when she went on sabbatical for one year. During her interview, she gave the impression that she was a determined teacher, eager to absorb relevant materials and later share her knowledge with her colleagues, and willing to teach and guide novice teachers. In addition, she enriched her high school students and encouraged them to participate in extra-curricular projects. Her impressions from the "basic training" and "MT training" stages show how she developed to the point that she became an ES superintendent for one year:

The "basic training" stage was very important to me. I was exposed to a variety of environmental subjects and to many new teaching and assessment tools, such as films, shared presentations, Google Docs, various apps, and so forth. All the teachers who participated with me were amazing! We became a close-knit group with mutual goals and eager to act. At this stage I was very active, sharing materials, conducting an educational program for teachers, and helping to organize the ES teacher annual conference.

As for the "master-training" stage, I guided two novice teachers. We had a wonderful relationship. I 
helped them with learning material, time management, how to conduct field trips, and how to carry out research assignments. My guidance helped their self-confidence. They knew they could always turn to me without any hesitation. On the other hand, I was also empowered by the process by knowing I can contribute from my knowledge and experience.

When the ES superintendent suggested that she take over her job for one year, Zoey eagerly accepted the challenge:

I think of environmental science as not just an academic discipline but a way of living. I wanted to implement environmental literacy among ES students and teachers, to raise awareness of environmental issues, and to spread the necessity for doing and acting in favor of the environment. I felt I could do so especially after the intensive training I had been through ... Now, a year later, I feel I had only minor success. I did meet with teachers and students and encouraged them to participate in environmental projects, and I was aware of local initiatives that were managed by ES students. Yet, overall, I feel frustrated because I really have any authority to initiate major changes due to the many regulations within the educational system.

Zoey's words show her frustration: although she did make some changes and has promoted ES as an important subject, administrational obstacles hindered her efforts for more widespread change.

\subsection{Insights of Participants Regarding the TSPD Model and "Leading Teachers"}

Participants who completed the second stage were asked to give their opinion of the TSPD model.

Their opinions were classified as (1) fully satisfied or (2) satisfied with reservation. $80 \%$ of the participants were very positive about this training model and thought it was an ideal format for becoming a MT. Farid, for example, mentioned these benefits:

This program enabled me to connect to my students, to their needs and desires. It allowed me to understand them and in this way to become a better teacher. This program enhanced my capabilities among my ES colleagues. Still, the most important gain was my empowerment in my private and professional lives. I feel I am now more devoted to my students, my colleagues, and the environment.

The other $20 \%$ expressed satisfaction, but stated that they had some reservations concerning some segments of the PD model. For example, Eli stated: "The overall program was a success. However, I believe that the 'master-teacher'stage shouldn't be combined with basic training. Many experienced teachers could be excellent tutors given proper qualification and should have access to such a course."

In Questionnaire 2, MT participants were asked to define in their own words what a "leading teacher" means to them. Their answers indicated that "leading teachers" show responsibility for the ES teacher community and are aware of its needs. For example, Dilia wrote: "A 'leading teacher' is one who contributes time, experience, and qualifications to enhance student learning, help novice teachers adjust to the educational system, and improve the educational system in general with ideas or materials he has developed." In addition, the respondents pointed out that "leading teachers" bring the theory learned in the course into practice among colleagues and students and enhance environmental awareness and willingness to act. In Mori's words: 'A 'leading teacher' empowers students and instills a deep commitment to the environment as well as practical implementation of environmental actions. A 'leading teacher' can also guide other teachers and enriching them with his knowledge, techniques, and insights." The overall consensus was that "leading teachers" set an example by showing commitment to their students and colleagues, and by actually acting in ways to help the natural and social environment.

\subsection{Interview with Course Leader Regarding the TSPD Model}

The course leader, Rachel, expressed her opinions regarding the entire process, from its beginning, through its implementation, and finally regarding its outcomes. We assumed that her insights and conclusions were an important supplement to the participants' points of view.

As Rachel explained, the initial idea was the ES superintendent's response to a lack of qualified staff to guide ES teachers. For this reason, the ES superintendent decided to plan, with Rachel's assistance and the authors of this article, a program aimed to prepare participants to become ES community leaders. The hope was that, ultimately, they could, in consultation with the ES superintendent, be assigned to specific roles in the system (guiding ES teachers, developing learning materials, etc.). Additionally, it would make them better pedagogues and empower them to become leaders in the ES teacher community. The "basic training" program was the result, and Rachel gave several examples of how they planned to do this: 
We planned to visit locations that encouraged participants to cherish the natural environment. We taught them about human environmental interactions, encouraged them to develop study units using a variety of teaching and assessment methods, and gave them the skills to become leaders. Since it was a mixed group of two sectors, the Arab and the Jewish sectors, I decided' from the beginning to divide them into mixed working groups to unify them into a close-knit community.

Reflecting on the process, however, they (Rachel, the ES superintendent, and the researchers) realized that at the end of the "basic training" stage, participants would not be as ready as they hoped they would be. Rachel reported:

At this point, we realized that this program should be considered a trial, and we needed to think of a more supportive and efficient way to turn the participants into role players in the ES educational system. Moreover, we realized we needed to supply ongoing support to sustain the teachers in their roles.

This, says Rachel, is what led to the development of the "MT training" stage:

We designed a continuation to the program by which we could support teachers - whom we assigned to each guide two novice teachers - through face-to-face meetings, e-mail, and online forums. We deemed this successful, and after one year, continued to the "independent implementation" stage where the ES superintendent assigned nine of them to different roles in the system: teachers' guides, members in the ES educational committee, or designing learning materials. One of the participants, Zoey, even replaced the ES superintendent when she was on sabbatical. Looking back, I think I have reasons to be pleased. I think we succeeded in our mission to empower teachers and give them ongoing support.

\section{Discussion and Conclusion}

The purpose of this study was to examine how a TSPD program influenced ES teacher performance in the classroom and empowered them to be leaders in the ES teacher community.

\subsection{Teacher Performance in the Classroom}

Revealing the teachers' performances in their classrooms suggests that, similar to other studies (Avalos, 2011; Dori \& Herscovitz, 2005; Tal \& Argaman, 2005), participating in a PD course increases teachers' pedagogical content knowledge and skills, and allows them to successfully implement new strategies into their teaching, particularly technological ones. The technological aspect is important: in today's world, computers and smartphones rule, sensors measure water and air quality, and augmented reality apps give convincing portrayals of the universe. Teachers must be willing and able to embrace technology and combine it into their daily teaching, yet being comfortable with the technology, especially for some adults, is not easy (Kang \& Yoon, 2008). Alongside the hurdle of mastering the technology, there is hesitation regarding class management (for example, the fear that the students will take control of the technology or be distracted by it) (Thomas, O'Bannon \& Bolton, 2013; Thomas, O'Bannon \& Britt, 2014). However, the fact that, in our study, almost half the teaching strategies mentioned concerned technological devices or applications shows that the teachers successfully confronted any uncertainty and introduced (more) technology in their classes.

Another strategy repeatedly mentioned was field trips pertaining to the subject matter. Numerous studies have indicated that field trips are a crucial part of any ES program and enable learners to develop environmental awareness and to observe and learn about environmental phenomena (Falk, 2005; Orion, 1993; Rickinson et al., 2004). Clearly, ES is a subject that should be accompanied by outdoor activity. Yet many teachers hesitate to go out with their students due to a myriad of reasons such as budget considerations, fear of losing control, lack of experience, or the inconvenience of teaching outdoors in unfamiliar settings and without the usual teaching tools. Sometimes the hesitation stems from laziness or an unwillingness to upset a familiar teaching routine (Behrendt \& Franklin, 2014; Rickinson et al., 2004).

For this reason, the course designers took participants to various outdoor environments during the "basic training" phase. The assumption was that being allowed to experience the preparations beforehand and some specific activities at the site would help teachers overcome some of their hesitance. And while fewer than a third of the teachers said they introduced field trips into their core lessons, the reason for this may not be their hesitance to take their students on field trips, but rather the awareness that they will be visiting three different environments during the "Environmental Workshop" unit later in the year, when they will have the opportunity to supplement their earlier lessons about specific environments. For example, when visiting an industrial park, the teacher can supplement their earlier lessons about air and water quality, hazardous waste, and urban design (Tal \& Abramovich, 2013). 
Regarding implementation of sustainability principles, it seems apparent that teachers who teach environmental science should integrate sustainability principles into the topics they teach-Therefore, it was disappointing to discover that the majority (67\%) of teachers only discussed general care for the environment when they taught about implementation of sustainability principles and did not encourage their students to take specific action.

\section{2 Teacher Performance in the ES Teacher Community and as Leaders}

The teachers' responses clearly showed that they became very involved in the ES teacher community, especially by sharing learning materials with other ES teachers. This agrees with observations made in other studies (e.g. Hallinger, Piyaman, \& Viseshsiri, 2017; Hofstein, 2005).

The participants who went on to the "MT training" stage showed success in helping their novice teachers. The program seemed to empower these participants with the appropriate knowledge and skills to guide their novice teachers. In addition, their acquired self-confidence allowed them to befriend the novice teachers, integrate them into the ES teacher community, and provide them with whom to turn to without fear of being judged. Their actions seem to not have gone unnoticed in the ES community: at the time of this writing, three of the participants are guiding other novice teachers who turned to them for help.

However, there are no signs that any of the participants are taking the initiative to lead. All those who are in leader roles today ( 9 out of 14) were assigned those roles as leaders, and continue to do so until today. This might imply that although participants possess the potential to lead after the basic-training phase, as has been shown in other cases (Hofstein, 2005), potential alone is not enough: one must have the desire to be a leader and be available for the position (Popper et al., 2004). Another condition to encourage leadership is a system whereby teachers can exercise leadership skills and obtain support at every stage (Howe \& Stubbs, 2003; Sprott, 2019). Our findings indicate that although the participants were eager to improve their functionality as pedagogues and felt they got adequate training (MT training stage) and support (even currently) to be leaders, they lack the initiative to be successful leaders. We would like to believe that with ongoing support, this may still be forthcoming, as other studies have reported the evolvement of leadership activities after participating in a PD program (Hofstein, 2005; Sprott, 2019).

With respect to PD programs for ES teachers, the program described herein - one which adds "master-teacher training" and "independent implementation" stages to encourage leadership in the ES community - is unique. The central goal of these additions was to empower and support participants in the implementation of their skills, and the program, per se, proved to be a success, since better than fifty percent of the participants who continued (9 out of 14) have taken on meaningful and important roles in the ES educational system. However, the number of teachers who were interested in continuing from the basic training stage to these additional stages was disappointing: only 14 teachers out of 31 . It is clear that something must be done to encourage teachers to pursue ongoing training.

One other area of concern must be mentioned, and this is the gap between the participants' descriptions about their interactions with their novice teachers and their definition of what a "leading teacher" means. While they all spoke of working "together" with their teachers, none of them defined "teamwork" or "partnership" as a component of leadership. Since teamwork is a vital characteristics of effective leadership (Fullan, 2003), it seems that leadership characteristics must be explicitly mentioned during the program.

To conclude, the TSPD model developed and described herein was deemed successful albeit with some reservation and with specific areas that need to be addressed. As a further note, although the model described herein was tested on ES teachers, we believe that the basic concepts are applicable to any teacher community and can be successfully utilized to empower and train teachers of any subject to become mentors (master-teachers).

\section{Acknowledgments}

We would like to thank Prof. David Ben-Chaim for his encouragement and support.

We also like to thank the ES superintendent, the course leader, and participant teachers for their fully and unconditional cooperation.

\section{References}

Abramovich, A., \& Loria, Y. (2015). The Long-Term Impact of an Education for Sustainability Course on Israeli Science \& Technology Teachers' Pro-Environment Awareness, Commitment and Behaviour. The Australian Journal of Environmental Education, 31, 1-16. https://doi.org/10.1017/aee.2015.31

Abramovich, A., \& Miedijensky, S. (2016). From Guided Teacher into a Leader: A Three-Stage Professional Development Model for Empowering Teachers. AERA annual meeting. Washington DC., U.S.A. 
Avalos, B. (2011). Teacher professional development in Teaching and Teacher Education over ten years. Teaching and Teacher Education, 27, 10-20. https://doi.org/10.1016/j.tate.2010.08.007

Bell, B., \& Gilbert, J. (1996). Teacher development: A model from science education. London: Falmer

Behrendt, M., \& Franklin T. (2014). A review of research on school field trips and their value in education. International Journal of Environmental and Science Education, 9(3), 235-245.

Borko, H., Koellner, K., \& Jacobs, J. (2014). Examining novice teacher leaders' facilitation of mathematics professional development. The Journal of Mathematical Behavior, 3, 149-167. https://doi.org/10.1016/j.jmathb.2013.11.003

Dawkins, K. R., \& Dickerson, D. L. (2007). Building a community of teacher learners in an earth/environmental science professional development opportunity. Journal of Geoscience Education, 55, 67-71. https://doi.org/10.5408/1089-9995-55.1.67

Desimone, L. M. (2009). Improving impact studies of teachers' professional development: Toward better conceptualizations and measures. Educational Researcher, 38, 181-199. https://doi.org/10.3102/0013189X08331140

Dietz, T., Dolšak, N., Ostrom, E., \& Stern, P. C. (2002). The drama of the common. In E. Ostrom, T. Dietz, N. Dulsak, P. Stern, \& S. Stonick (Eds.). The Drama of the Commons (pp. 3-34). Washington, DC: National Academy Press.

Dori, Y. J., \& Herscovitz, O. (2005). Case-based long-term professional development of science teachers. International Journal of Science Education, 27, 1413-1446. https://doi.org/10.1080/09500690500102946

Falk, J. H. (2005). Free-choice environmental learning: Framing the discussion. Environmental Education Research, 11, 265-280. https://doi.org/10.1080/13504620500081129

Fortino, C. (1997). Leaders in environmental education: the cascade of influence. Environmental Education Research, 3, 203-223. https://doi.org/10.1080/1350462970030208

Fullan, M. (2003). The Moral Imperative of School Leadership. Thousand Oaks, CA: Corwin Press; Toronto, Ontario Principals' Council.

Gaines, R. E., Osman, D. J., Maddocks, D. L. S., Warner, J. C., ... Schallert, D. L. (2019). Teachers' emotional experiences in professional development: Where they come from and what they can mean. Teaching and Teacher Education, 77, 53-65. https://doi.org/10.1016/j.tate.2018.09.008

Gallagher, D. R. (2012). Why environmental leadership. In B. R. Gallagher, (Ed.). Environmental Leadership: A Reference Handbook (pp. 3-10). Sage Publication, Thousand Oaks, California. https://doi.org/10.4135/9781452218601.n1

Hallinger, P., Piyaman, P., \& Viseshsiri, P. (2017). Assessing the effects of learning-centered leadership on teacher professional learning in Thailand. Teaching and Teacher Education, 67, 464-476. https://doi.org/10.1016/j.tate.2017.07.008

Hargreaves, A., \& Fink, D. (2004). The seven principles of sustainable leadership. Educational Leadership, 61, $8-13$.

Harrison Berg, J., Carver, C. L., \& Mangin, M. M. (2014). Teacher leader model standards: Implications for preparation, policy, and practice. Journal of Research on Leadership Education, 9, 195-217. https://doi.org/10.1177/1942775113507714

Hofstein, A. (2005). Chemistry teachers' professional development for the implementation of new content and pedagogical standards. Chemical Education International (IUPAC), 6(1).

House, R. J. (2004). Culture, leadership, and organizations: The GLOBE study of 62 societies. Thousand Oaks, CA: Sage.

Howe, A. C., \& Stubbs, H. S. (2003). From science teachers to teacher leader: Leadership development as meaning making in a community of practice. Science Teacher Education, 87, 281-297. https://doi.org/10.1002/sce.10022

Israeli Ministry of Education, 2016. Environmental science curriculum. Retrieved from http://cms.education.gov.il/EducationCMS/Units/Mazkirut_Pedagogit/MadaeHasvivva/TochnitLimudimCh adash/

Kang, N. E., \& Yoon, W. C. (2008). Age and experience related user behavior differences in the use of 
complicated electronic devices. International Journal of Human-Computer Studies, 66, 425-437. https://doi.org/10.1016/j.ijhcs.2007.12.003

Lincoln, Y. S., \& Guba, E. G. (2000). Paradigmatic controversies, contradictions, and emerging confluences. In N. K. Denzin, \& Y. S. Lincoln (Eds.), The Handbook Of Qualitative Research (pp. 163-188), Beverly Hills, CA: Sage, 2nd ed.

Loucks-Horsley, S., Stiles, K. E., Mundry, S., Love, N., \& Hewson, P. W. (2009). Designing Professional Development for Teachers of Science and Mathematics. (Third Edition). Thousand Oaks, CA: Crowin.

Manolis, J. C., Chan, K. M., Finkelstein, M. E., Stephens, S., Nelson, C. R., Grant, J. B., \& Dombeck, M. P. (2008). Leadership: a new frontier in conservation science. Conservation Biology, 23, 879-886. https://doi.org/10.1111/j.1523-1739.2008.01150.x

Marshall, C., \& Rossman, G. B. (2014). Designing Qualitative Research (6th edition) CA: Sage.

Northouse, P. G. (2010). Leadership: Theory and practice (5th ad). Thousand Oaks, CA: Sage.

Orion, N. (1993). A Model for the development and implementation of field trips as an integral part of the science curriculum. School Science and Mathematics, 93, 325-331. https://doi.org/10.1111/j.1949-8594.1993.tb12254.x

Popper, M., Amit, K., \& Gal, R. (2004). The capacity to lead: major psychological differences between leaders and non-leaders. Military Psychology, 16, 245-263. https://doi.org/10.1207/s15327876mp1604_3

Rickinson, M., Dillon, J., Teamey, K., Morris, M., Choi, M. Y., Sanders, D., \& Benefield, P. (2004). A Review of Research on Outdoors Learning. National Foundation for Educational Research (NFFR), UK.

Sprott, R. A. (2019). Factors that foster and deter advanced teachers' professional development. Teaching and Teacher Education, 77, 321-331. https://doi.org/10.1016/j.tate.2018.11.001

Stern, P. C. (2000). Toward a coherent theory of environmentally significant behavior. Journal of Social Issues, 56, 407-424. https://doi.org/10.1111/0022-4537.00175

Stern, P. C., Dietz, T., Abel, T., Guagnano, G.A., \& Kalof, L. (1999). A value-belief-norm theory of support for social movements: The case of environmentalism. Research in Human Ecology, 6, 81-97.

Supovitz, J. A., \& Turner, H. M. (2000). The effects of professional development on science teaching practices and classroom culture. Journal of Research in Science Teaching, 37, 963-980. https://doi.org/10.1002/1098-2736(200011)37:9<963::AID-TEA6>3.0.CO;2-0

Tal, T., \& Abramovitch, A. (2013). Activity and action: Bridging environmental sciences and environmental education. Research in Science Education, 43, 1665-1687. https://doi.org/10.1007/s11165-012-9327-9

Tal, R. T. \& Argaman, S. (2005). Characteristics and Difficulties of Teachers Who Mentor Environmental Inquiry Projects. Research in Science Education, 35, 363-394. https://doi.org/10.1007/s11165-004-8163-y

Thomas, K. M., O'Bannon, B. W., \& Bolton, N. (2013). Cellphones in the classroom: teachers' perspectives of inclusion, benefits, and barriers, Computers in the Schools, 30, 295-308. https://doi.org/10.1080/07380569.2013.844637

Thomas, K.M., O’Bannon, B. W., \& Britt, V. G. (2014). Standing in the schoolhouse door: Teacher perceptions of mobile phones in the classroom, Journal of Research on Technology in Education, 46, 373-395. http://dx.doi.org/10.1080/15391523.2014.925686

Tuckman, B. W., \& Harper, B. E. (2012). Conducting Educational Research (6th ed). Lanham, Maryland: Rowman \& Littlefield Publishers, sixth ed. pp. 243-286.

Van Driel, J. H., \& Berry, A. (2012). Teacher professional development focusing on pedagogical content knowledge. Educational Researcher, 41, 26-28. https://doi.org/10.3102/0013189X11431010

Wetzler, J. (2010). Developing teachers as leaders. Change: The Magazine of Higher Learning, 42, 25-32. https://doi.org/10.1080/00091383.2010.523403

York-Barr, J., \& Duke, K. (2004). What do we know about teacher leadership? Findings from two decades of scholarship. Review of Educational Research, 74(3), 255-316. https://doi.org/10.3102/00346543074003255

\section{Copyrights}

Copyright for this article is retained by the author(s), with first publication rights granted to the journal.

This is an open-access article distributed under the terms and conditions of the Creative Commons Attribution license (http://creativecommons.org/licenses/by/4.0/). 